\title{
Ectrodactyly or Lobster Claw Syndrome,
}

\author{
"Dr. Dama Aneesha, Dr. Geetha Lakshmi, Dr .K .Saraswathi \\ ${ }^{1}$ Postgraduate, Dept Of Obstetrics And Gynecology, Sreebalaji Medical College \& \\ Hospital, Chennai, India. \\ ${ }^{2}$ Assistant Professor Sreebalaji Medical College \& Hospital, Chennai, India. \\ ${ }^{3}$ Head Of The Department, SBMCH \\ Corresponding author: *Dr. Dama Aneesha
}

\begin{abstract}
Split-hand/split-foot malformation is a rare limb malformation with median clefts of the hands and feet and aplasia/hypoplasia of the phalanges, metacarpals and metatarsals. When present as an isolated anomaly, it is usually inherited as an autosomal dominant form We report a case of autosomal dominant inheritance and discuss the antenatal diagnosis, genetic counseling and treatment for the malformation.

keywords: autosomal dominant,split hand/split foot malformation,syndactyly
\end{abstract}

\section{Introduction}

Split-hand/split-foot malformation (SHFM) / ectrodactyly, also known as "lobster claw hand," is a limb malformation involving the central rays of the autopod and presenting with syndactyly, median clefts of the hands and feet and aplasia / or hypoplasia of the phalanges, metacarpals and metatarsals. There is median cleft in the hand and feet due to the absence of the central digital rays, which gives the appearance of a lobster.

We report a case with ectrodactyly involving right hand with shortening of forearm

\section{Case report}

A male baby, was born in hospital. G2P1L1 mother had no significant medical history. There was no history of consanguinity or any other relevant family history. She had uneventful antenatal period and had received all the supplements. There was no gestational diabetes mellitus, pregnancy induced hypertension. Antenatal ultrasound at local health centre showed no congenital abnormalities. After a term pregnahncy of 38 weeks, ceasarian section was performed for previous lscs-breech. Birth weight was 2.9 kilograms.No resuscitation was required. There was no family history of EEC or other genetic abnormality in the family.

Physical examination revealed the following:
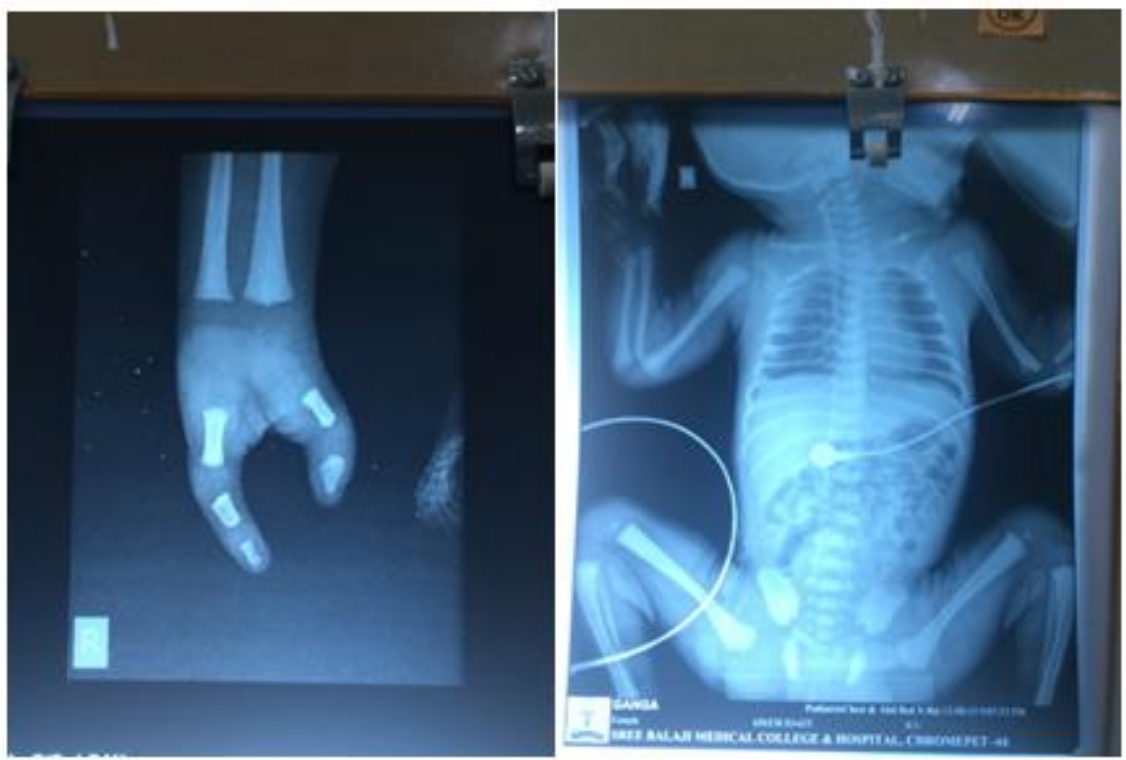

There were median clefts of right hand shortening of right forearm .. In the right hand, there was syndactyly of ring finger and that of the thumb shortening of forearm the left hand was normal. The X-rays of the right hand showed normal metacarpals in both the hands but absence of middle and terminal phalanges of the middle finger and ring finger in right hand. Both the feet were normal.his both legs were normal.systemic 
examination of this patient did not reveal any abnormality.usg did not show any abnormality.echo did not reveal any abnormality.hair ,teeth were normal.there was no other congenital abnormality found.

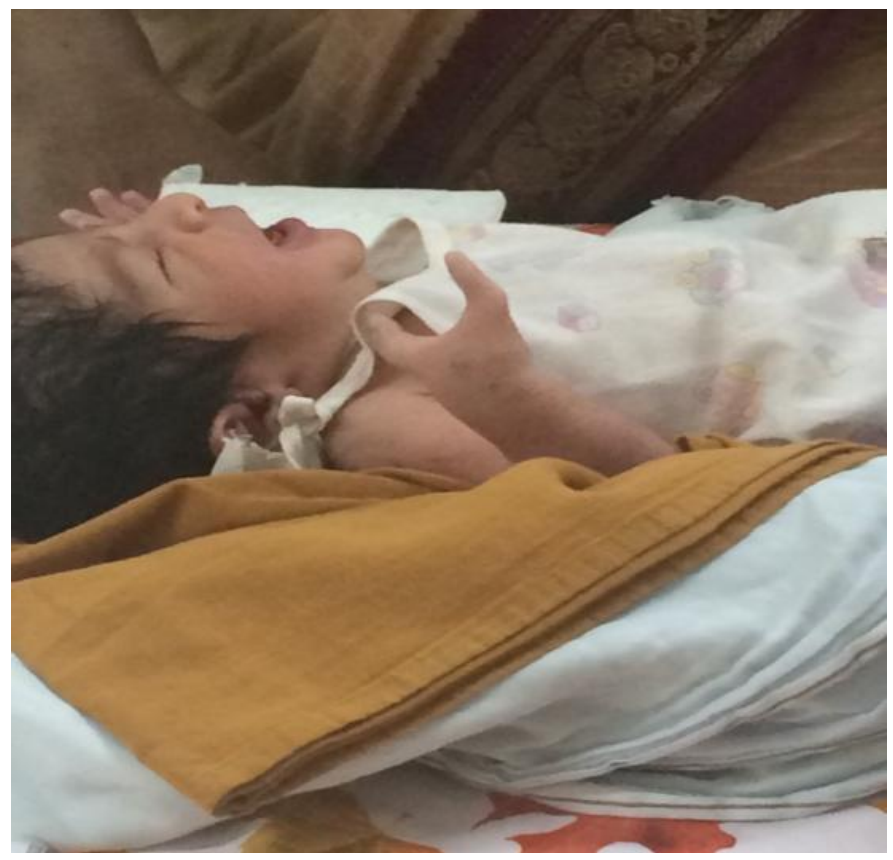

\section{Disscussion}

Ectrodactyly, ectodermal dysplasia, and cleft lip/palate syndrome syndrome is a rare genetic disorder with an incidence of around 1 in 90,000 in general population 1 with males and females equally affected. It is known with various names that includes split hand-split foot-ectodermal dysplasia-cleft syndrome or split hand, cleft hand, or lobster claw hand/foot . It has been postulated to be caused by mutation in TP63 gene. EEC syndrome is usually inherited as an autosomal dominant trait although sporadic cases have also been reported. TP63 gene is located on the long arm (q) of chromosome 3 (3q27). TP63 encodes a homolog of the tumor suppressor p53 gene. TP63 has been found to have around six isoforms, with their prime function being modulating gene expression. There are other four syndromes reported in medical literature that are caused by mutations of the p63 gene including Ankyloblepharon-Ectodermal dysplasia-Clefting (AEC syndrome), AcroDermato-Ungueal-Lacrimal-Tooth (ADULT syndrome), Rapp-Hodgkin (RHS syndrome), and LimbMammary (LMS syndrome) Different overlapping diseases with EEC and their main features are shown. Disease Clinical features Ankyloblepharon-ectodermal dysplasia-clefting (AEC syndrome) Characterized by ankyloblepharon (congenital adhesions of the eyelids), ectodermal dysplasia, brittle white, and sparse eyebrows and eyelashes, otitis media, nevi, and orofacial clefts $(6,7)$ Acrodermato-ungueallacrimal-tooth (ADULT syndrome) Characterized by ectrodactyly, syndactyly, excessive freckling, dry skin, dysplastic nails, lacrimal duct atresia, primary hypodontia, and early loss of permanent teeth $(8,9)$ Rapp-Hodgkin (RHS syndrome) Characterized by cleft lip and palate, small mouth, narrow nose, coarse and wiry hairs progressing to alopecia in adults, oligodontia or anodontia, hypoplasia of the nails, abnormalities of the lacrimal ducts, deformed ears and ear canals, hyperplastic mucosa, cheilitis angularis, renal dysplasia, inguinal hernia, hypospadias in males, urethral reflux, and perioral ulcer Limb-mammary (LMS syndrome) Characterized by mammary gland and/or nipple hypoplasia, lacrimal duct obstruction, cleft palate with or without bifid uvula, dystrophic nails, hypohydrosis, and teeth defects. There is considerable overlap among these disorders and some researchers have postulated them as different spectrum of same disorder due to differential expression of genes. There has been rare situation in which patients affected with EEC syndrome are noted to have chromosomal deletions or translocations on the long arm of chromosome 7 (7q11.2-q21.3 and 9p12) (4, 5). There are multiple classifications for cleft hand defined in medical literature but one classified by Manske and Halikis is most commonly used. This proposed classification is based on the characteristics of the thumb web, which are more important to the function of the hand than are the central deficiency features. Ectrodactyly is usually seen as either complete absence of or malformation of one or more fingers or toes. Patients generally have median cleft in upper and lower limbs, which makes the affected limbs look like a lobster claws and hence the name given. This lobster claw is thought to arise as a result of a wedge-shaped defect of the apical ectoderm of the limb buds . Sometimes all four limbs involvement may be seen, even though this is a rare phenomenon. The majority of the patients usually have mild limb abnormality and very rarely may be unaffected. The patients of EEC may 
sometimes have webbing or fusion (syndactyly) of the fingers and/or toes . In some cases, syndactyly may be the only limb defect that is seen. Affected children may have other facial anomalies that includes cleft lip/palate, maxillary hypoplasia, long philtrum, and choanal atresia or can be normal too. The spectrum of dermatological manifestation associated with ectodermal dysplasia is variable and include hyper keratosis, thickened scaly skin to hypo pigmented dry skin with poor hair growth. Scalp hair as well as eyebrows may be sparse, wiry, and with hypo pigmented hair. Additional symptoms can include dysplastic nails and peg-shaped teeth. Tooth decay (dental caries) is very common clinical finding as seen in our patient and is often very severe and sometimes tooth enamel may be abnormal. There may be associated reduction in activity or complete absence of exocrine glands of the body including the sweat, salivary, lacrimal, and sebaceous glands. Abnormality of the sweat glands usually leads to heat intolerance and fever as an effect of hypohydrosis whereas absence of salivary glands can lead to xerostomia. There can also be associated abnormalities in other glands including lacrimal gland causing xerophthalmia as well keratitis. Some individuals with EEC syndrome have developed hearing loss. Some individuals may have endocrinal problems like hypopituitarism and underdeveloped thymus. There have been few rare case reports of associated anomalies of the genitourinary system with various spectrum of malformations ranging from renal agenesis, renal stone to hydronephrosis . Intelligence is usually preserved, however there may delay in speech development, which is due to associated hearing loss. Few long-term case report has shown their progression to Hodgkin lymphoma. There has been one case report of EEC syndrome associated with congenital heart disease (Ventricular septal defect with aortic regurgitation.

Management of this condition involves multidisciplinary involvement and starts with detailed evaluation with imaging technique of the affected limbs, ophthalmological evaluation, hearing assessment, renal ultrasound, 2D-echocardiography, thyroid screening, and skin biopsy. The confirmatory diagnosis is by molecular genetic testing. The confirmation of EEC syndrome can be done by molecular genetic testing for TP63 gene mutation. Patients who are diagnosed to have EEC on physical examination, mutational gene analysis of the TP63 gene should be the priority test and if it shows negative results then other test for diagnosing chromosomal abnormalities should be considered. Antenatal diagnosis is feasible using the molecular genetic testing and samples are obtained using chorionic villus sampling, which should be performed if there is suspicion on fetal ultrasound Treatment is largely supportive and involves managing the various anomalies and involves a team of health care personal. Orthopedic management in form of limb reconstructive surgery may be considered in patients that are having functional disability such as ectrodactyly, syndactyly, cleft lip, or palate. If teeth are missing, artificial dentures may be necessary and oral hygiene makes an important part of management. Use of artificial tears and emollients may be necessary for ectodermal dysplasia for prevention of evaporative eye loss.

\section{Conclusion}

EEC syndrome patients have various manifestation with various system involvement. Genetic analysis is the key for correct diagnosis of the EEC syndrome. Treatment involves multidisciplinary team, which takes care of associated malformations. Regular and strict follow up should be done of these patients. Prenatal counseling and genetic screening should be done for all couples who have previous EEC syndrome affected neonate.

\section{Reference}

[1]. Di Iorio E, Kaye SB, Ponzin D, Barbaro V, Ferrari S, Böhm E, et al. Limbal stem cell deficiency and ocular phenotype in ectrodactyly-ectodermal dysplasia-clefting syndrome caused by p63 mutations. Ophthalmology (2012) 119(1):74-83. doi:10.1016/j.ophtha.2011.06.044

[2]. Yang A, Kaghad M, Wang Y, Gillett E, Fleming MD, Dötsch V, et al. p63, a p53 homolog at 3q27-29, encodes multiple products with transactivating, death-inducing, and dominant-negative activities. Mol Cell (1998) 2(3):305-16. doi:10.1016/S10972765(00)80275-0

[3]. Brunner HG, Hamel BCJ, Van Bokhoven H. The p63 gene in EEC and other syndromes. J Med Genet (2002) 39(6):377-81. doi:10.1136/jmg.39.6.377

[4]. Fukushima Y, Ohashi H, Hasegawa T. The breakpoints of the EEC syndrome (ectrodactyly, ectodermal dysplasia and cleft lip/palate) confirmed to 7q11.21 and 9p12 by fluorescence in situ hybridization. Clin Genet (1993) 44(1):50. doi:10.1111/j.13990004.1993.tb03843.x

[5]. Qumsiyeh MB. EEC syndrome (ectrodactyly, ectodermal dysplasia and cleft lip/palate) is on 7p11.2-q21.3. Clin Genet (1992) 42(2):101. doi:10.1111/j. 1399-0004.1992.tb03149.x

[6]. Van Straten C, Butow K-W. Gene p63: in ectrodactyly-ectodermal dysplasia clefting, ankyloblepharon-ectodermal dysplasia, Rapp-Hodgkin syndrome. Ann Maxillofac Surg (2013) 3(1):58-61. doi:10.4103/2231-0746.110085

[7]. Sawardekar SS, Zaenglein AL. Ankyloblepharon-ectodermal dysplasiaclefting syndrome: a novel p63 mutation associated with generalized neonatal Frontiers in Pediatrics | www.frontiersin.org 3 June 2015 | Volume 3 | Article 51 Sharma et al. EEC syndrome with TOF erosions. Pediatr Dermatol (2011) 28(3):313-7. doi:10.1111/j.1525-1470.2010. 01207.x

[8]. Berk DR, Armstrong NL, Shinawi M, Whelan AJ. ADULT syndrome due to an R243W mutation in TP63. Int J Dermatol (2012) 51(6):693-6. doi:10.1111/j. 1365-4632.2011.05375.x

[9]. Avitan-Hersh E, Indelman M, Bergman R, Sprecher E. ADULT syndrome caused by a mutation previously associated with EEC syndrome. Pediatr Dermatol (2010) 27(6):643-5. doi:10.1111/j.1525-1470.2010.01131.x 
[10]. Bougeard G, Hadj-Rabia S, Faivre L, Sarafan-Vasseur N, Frébourg T. The RappHodgkin syndrome results from mutations of the TP63 gene. Eur J Hum Genet (2003) 11(9):700-4. doi:10.1038/sj.ejhg.5201004

[11]. Clements SE, Techanukul T, Holden ST, Mellerio JE, Dorkins H, Escande F, et al. Rapp-Hodgkin and Hay-Wells ectodermal dysplasia syndromes represent a variable spectrum of the same genetic disorder. Br J Dermatol (2010) 163(3):624-9. doi:10.1111/j.1365-2133.2010.09859.x

[12]. Van Bokhoven H, Jung M, Smits AP, van Beersum S, Rüschendorf F, van Steensel M, et al. Limb mammary syndrome: a new genetic disorder with mammary hypoplasia, ectrodactyly, and other hand/foot anomalies maps to human chromosome $3 \mathrm{q} 27$. Am J Hum Genet (1999) 64(2):538-46. doi:10.1086/302246

[13]. Van Bokhoven H, Hamel BC, Bamshad M, Sangiorgi E, Gurrieri F, Duijf PH, et al. p63 Gene mutations in eec syndrome, limbmammary syndrome, and isolated split hand-split foot malformation suggest a genotypephenotype correlation. Am J Hum Genet (2001) 69(3):481-92. doi:10.1086/323123

[14]. Manske PR, Halikis MN. Surgical classification of central deficiency according to the thumb web. J Hand Surg. (1995) 20(4):687-97. doi:10.1016/ S0363-5023(05)80293-X

[15]. Duijf PHG, van Bokhoven H, Brunner HG. Pathogenesis of split-hand/splitfoot malformation. Hum Mol Genet (2003) 12(Spec No 1):R51-60. doi:10.1093/ hmg/ddg090

[16]. Agrawal A, Agrawal R, Singh R, Agrawal R, Agrawal S. Lobster claw deformity. Indian J Dent Res (2014) 25(2):243-7. doi:10.4103/0970-9290.135935

[17]. Patel A, Sharma D, Yadav J, Garg E. Split hand/foot malformation syndrome (SHFM): rare congenital orthopaedic disorder. BMJ Case Rep (2014) 2014. doi:10.1136/bcr-2014-204731

[18]. Malvankar DD, Sacchidanand S, Mallikarjun M. Ectrodactyly, ectodermal dysplasia, and cleft lip-palate (EEC) syndrome without clefting: a rare case report. Dermatol Online J (2012) 18(2):5.

[19]. Sankhyan N, Kaushal RK, Sarin S. Ectodermal dysplasia, ectrodactyly, cleft lip/palate syndrome without ectrodactyly. Dermatol Online J (2006) 12(4):5.

[20]. Thakkar S, Marfatia Y. EEC syndrome sans clefting: variable clinical presentations in a family. Indian J Dermatol Venereol Leprol (2007) 73(1):46-8. doi:10. 4103/0378-6323.30653

[21]. Knaudt B, Volz T, Krug M, Burgdorf W, Röcken M, Berneburg M. Skin symptoms in four ectodermal dysplasia syndromes including two case reports of Rapp-Hodgkin-syndrome. Eur J Dermatol (2012) 22(5):605-13. doi:10.1684/ ejd.2012.1787

[22]. Joseph R, Nath SG. Association of generalized aggressive periodontitis and ectrodactyly-ectodermal dysplasia-cleft syndrome. Indian J Hum Genet. (2012) 18(2):259-62. doi:10.4103/0971-6866.100793

[23]. Elmann S, Hanson SA, Bunce CN, Shinder R. Ectrodactyly ectodermal dysplasia clefting (EEC) syndrome: a rare cause of congenital lacrimal anomalies. Ophthal Plast Reconstr Surg (2015) 31(2): e35-

[24]. 24. Kaercher T. Ocular symptoms and signs in patients with ectodermal dysplasia syndromes. Graefes Arch Clin Exp Ophthalmol (2004) 242(6):495-500. doi:10. 1007/s00417-004-0868-0

[25]. Kumar HN, Kugar TS, Rao RJ, Kodkany S. EEC syndrome. Indian J Ophthalmol (2007) 55(2):162-3. doi:10.4103/03014738.30725

[26]. Roelfsema NM, Cobben JM. The EEC syndrome: a literature study. Clin Dysmorphol (1996) 5(2):115-27. doi:10.1097/00019605-199604000-00003

[27]. Hatipoglu N, Kurtoglu S, Büyükayhan D, Akçakus M. Hypothalamopituitary insufficiency associated with ectrodactylyectodermal dysplasiaclefting syndrome. J Clin Res Pediatr Endocrinol. (2009) 1(5):252-5. doi:10. 4274/jcrpe.v1i5.252

[28]. Shawky RM, Elsayed SM, Sadik DI, Gad S, Seifeldin NS. Adipsic hypernatremia and bilateral renal stones in a child with ectrodactyly-ectodermal dysplasia-cleft lip-palate (EEC) syndrome. Genet Couns. (2010) 21(2):215-20.

[29]. London R, Heredia RM, Israel J. Urinary tract involvement in EEC syndrome. Am J Dis Child (1985) 139(12):1191-3.

[30]. Balci S, Engiz O, Okten G, Sipahier M, Gursu G, Kandemir B. A 19-year followup of a patient with type 3 ectrodactylyectodermal dysplasia-clefting syndrome who developed non-Hodgkin lymphoma. Oral Surg Oral Med Oral Pathol Oral Radiol Endod (2009) 108(3):e91-5. doi:10.1016/j.tripleo.2009.04.043

[31]. Valenzise M, Arrigo T, De Luca F, Privitera A, Frigiola A, Carando A, et al. R298Q mutation of p63 gene in autosomal dominant ectodermal dysplasia associated with arrhythmogenic right ventricular cardiomyopathy. Eur J Med Genet (2008) 51(5):497-500. doi:10.1016/j.ejmg.2008.05.005

[32]. Rios LT, Araujo Júnior E, Caetano ACR, Nardozza LM, Moron AF, Martins MG. Prenatal diagnosis of EEC syndrome with "lobster claw" anomaly by 3D ultrasound. J Clin Imaging Sci. (2012) 2:40. doi:10.4103/2156-7514.99153

[33]. Buss PW, Hughes HE, Clarke A. Twenty-four cases of the EEC syndrome: clinical presentation and management. J Med Genet (1995) 32(9):716-23. doi:10. 1136/jmg.32.9.716

[34]. Pettit S, Campbell PR. Ectrodactyly-ectodermal dysplasia-clefting syndrome: the oral hygiene management of a patient with EEC. Spec Care Dentist (2010) 30(6):250-4. doi:10.1111/j.1754-4505.2010.00162.x

[35]. Ota Y, Matsumoto Y, Dogru M, Goto E, Uchino Y, Endo K, et al. Management of evaporative dry eye in ectrodactylyectodermal dysplasia-clefting syndrome. Optom Vis Sci (2008) 85(9):E795-801. doi:10.1097/OPX.0b013e31818527cd

[36]. Sharma D, Pandita A, Murki S, Oleti T. Lobster claw hand foot syndrome: rare congenital orthopedic disorder. J Neonatal Biol. (2014) 3(5):10001-102. doi:10.4172/2167-0897.1000I.102 C

"Dr. Dama Aneesha. "Ectrodactyly or Lobster Claw Syndrome,." IOSR Journal of Dental and Medical Sciences (IOSR-JDMS) 16.7 (2017): 46-49. 